\title{
Acknowledging and Supplanting White Supremacy Culture in Science Communication and STEM: The Role of Science Communication Trainers
}

\author{
Karlisa A. Callwood ${ }^{1,2 \dagger}$, Marissa Weiss ${ }^{2,3 * t}$, Rose Hendricks ${ }^{2,4 \neq}$ and Temis G. Taylor ${ }^{2,5,6 \neq}$ \\ ${ }^{1}$ Perry Institute for Marine Science, Waitsfield, VT, United States, ${ }^{2}$ Science Communication Trainers Network, Beaverton, OR, \\ United States, ${ }^{3}$ Department of Civil Engineering, University of Massachusetts, Amherst, MA, United States, ${ }^{4}$ The American \\ Society for Cell Biology, Rockville, MD, United States, ${ }^{5}$ Exact Communication, Fort Greene, NY, United States, ${ }^{6}$ Department \\ of Environment and Society, Utah State University, Logan, UT, United States
}

OPEN ACCESS

Edited by:

Ingrid Lofgren,

University of Rhode Island,

United States

Reviewed by:

Merryn McKinnon,

Australian National University, Australia

Bruno Takahashi,

Michigan State University,

United States

*Correspondence:

Marissa Weiss

marissaweiss@umass.edu

${ }^{t}$ These authors have contributed equally to this work and share first

authorship

FThese authors have contributed equally to this work and share last authorship

Specialty section

This article was submitted to Science and Environmental Communication

a section of the journal

Frontiers in Communication

Received: 01 October 2021 Accepted: 28 January 2022

Published: 25 February 2022

Citation:

Callwood KA, Weiss M, Hendricks $R$ and Taylor TG (2022) Acknowledging and Supplanting White Supremacy Culture in Science Communication and STEM: The Role of Science Communication Trainers.

Front. Commun. 7:787750

doi: 10.3389/fcomm.2022.787750
Racism remains a root cause of underrepresentation of Black, Indigenous, and Latinx scholars across STEM. It also contributes to a lack of diversity in science communication, the types of science stories that are told, and the communities science communicators seek to engage. Racism is omnipresent in STEM, from education to research to science communication (SciComm), because STEM institutions operate within a culture systematically privileging Whiteness, i.e., a White supremacy culture (WSC), that dictates the norms and practices that most in these fields heedlessly accept and replicate. In this Perspective, we acknowledge the ways in which SciComm and SciComm training perpetuate WSC and examine how SciComm trainers can use their power to dismantle it. SciComm trainers pioneer new methods of sharing ideas and influence the culture of STEM, so are uniquely situated to bring about systemic change to address these problems in SciComm, STEM, and society, starting with four core themes for action: (1) Authentic Interrogation, Acknowledgment, and Accountability; (2) Representation; (3) Culturally Responsive Practice; and (4) Inclusion. We also describe our current work, which builds upon the Key Traits of Inclusive SciComm identified by leaders in the field, to co-create a framework to guide authentic, culturally competent, and inclusive SciComm. The draft framework integrates the Key Traits across spheres of influence (e.g., self, interpersonal, community, institution, society: politics and culture), with the ultimate goal of using SciComm to supplant WSC across these spheres of influence, with new cocreated norms centering minoritized scholars, science communicators, and audiences in STEM.

Keywords: White supremacy culture, science communication training, cultural norms, equity, inclusion

\section{INTRODUCTION}

Racism is a root cause of underrepresentation of Black, Indigenous, and Latinx scholars across STEM. It also contributes to a lack of diversity in science communication, the types of science stories that are told, and the communities who are engaged. Racism is omnipresent in STEM, from education to research to science communication (SciComm), because STEM institutions ${ }^{1}$ operate

${ }^{1}$ STEM institutions refers to the STEM enterprise collectively, including higher education, non-profit research and educational organizations, government research labs and agencies, and corporate STEM research institutions. 
within a system that advantages White people, termed by Jones and Okun in a 2001 article, White Supremacy Culture (WSC) (Jones and Okun, 2001).

Jones and Okun identified 15 characteristics of WSC, including perfectionism, paternalism, power hoarding, worship of the written word, sense of urgency, belief in one right way, and defensiveness (see Table 1). WSC is embedded in the design of our institutions. It dictates the norms and practices that most in these fields heedlessly accept and replicate. Due to its pervasive nature, WSC is difficult for many to see and to process, thereby making it equally as difficult to address.

Our purpose in describing WSC in STEM institutions and SciComm is to name it so we can see it and change it (Bryant et al., 2021). Suggesting that WSC harms minoritized scholars in STEM may cause some to respond defensively or express disbelief (Handley et al., 2015; Bryant et al., 2021). Rather than dismissing the suggestion, we argue that important questions to consider are:

- Who does WSC in STEM harm, and how are they harmed?

- What is the role of SciComm in perpetuating and dismantling WSC in STEM?

- Who is responsible for designing and implementing solutions?

Here we offer our responses to these questions, with the following intentions: We write from the perspective of science communication trainers, complicit in a system that causes harm, with a desire to work for change from within our community of professionals. We encourage you to reflect on your own answers; to lean into these questions to determine what actions you can take to create a better, stronger culture in STEM; and if any feelings of discomfort, anger, or defensiveness arise, to acknowledge and reflect on your experiences in STEM and SciComm that shape your perspectives.

\section{Who Does WSC in STEM Harm, and How Are They Harmed?}

Underrepresented scholars in STEM are speaking about the ways they are harmed by WSC in STEM via social media (\#BlackIn, as described by Ortega, 2021); affinity, empowerment and advocacy groups (500 Women Scientists, 2016; Academics for Black Survival Wellness, 2020); presentations (Baxter, 2021); and film (Cheney and Shattuck, 2020). These personal narratives illustrate trends reported in publications documenting disproportionate barriers and lost opportunities for Black scholars in STEM (Lee, 2020; McGee, 2020; Easley, 2021). WSC places the burden on underrepresented individuals to prove a causal relationship between the hostile environment in STEM and the demographics of STEM institutions. The most common tropes are that an individual's attitude, aptitude, or interests determine whether they succeed in STEM (Henry, 2010). However, the environment-the culture of STEM-remains uninterrogated. We argue that the correct order of operations is to first interrogate the role of WSC in STEM for determining the demographics of STEM institutions. Only once STEM leaders whose actions perpetuate WSC, relinquish their gatekeeping role determining who is considered a scientist, can we begin to consider the role of attitude, aptitude, and interests.

\section{What Is the Role of SciComm in Perpetuating and Dismantling WSC in STEM?}

The most conspicuous way SciComm trainers and practitioners of SciComm (collectively, SciCommers ${ }^{2}$ ) perpetuate WSC is by disproportionately training, elevating, and amplifying White scientists and their research (Dawson, 2018; Dudo et al., 2021). While improving access to training and elevating and amplifying the voices of underrepresented scientists is one part of the solution, we also need new models, frameworks, and cultural change in SciComm and STEM in order for STEM to truly be an authentic multicultural enterprise.

SciComm trainers have a history of being cultural changeagents. They pioneer new methods of sharing ideas and influence the culture of STEM, so are uniquely situated to bring about systemic change. SciCommers are contributing to a shift in the culture of science by placing increased value on the critical roles of outreach and engagement (Christopherson et al., 2018). The next frontier is cultural change needed to dismantle WSC in STEM.

\section{Who Is Responsible for Designing and Implementing Solutions?}

In the remainder of the article, we will draw on the literature, the reported experiences of our colleagues, and our own experiences as scientists and SciCommers to document the fingerprints of WSC in the culture of STEM institutions, the harm caused by it, and foundations for doing better. Below, we suggest four key themes for immediate action, and describe our current work, to co-create a framework to help guide authentic, culturally competent, and inclusive SciComm. The draft framework integrates Canfield and Menezes (2020)'s Key Traits of Inclusive SciComm across multiple spheres of influence (e.g., self, interpersonal, community, institution, society: politics and culture) (Figure 1), with the ultimate goal of using SciComm to supplant WSC across these levels of influence with new co-created norms centering minoritized scholars, science communicators, and audiences in STEM.

\section{WSC in STEM and SciComm Does WSC Exist in STEM?}

Most (if not all) of the WSC characteristics described by Jones and Okun (2001) are valued as essential for success in our field (see Table 1). White supremacist norms are prevalent in college admissions and hiring, awarding funding, determining who gets published and who has access to what is published, which communities and audiences are prioritized for communications, and who has a say in what is studied and why (Stevens et al., 2021; Taffe and Gilpin, 2021). Accordingly, institutional and systemic change is needed to mitigate the WSC characteristics woven into the fabric of our STEM institutions and standards of practice.

\footnotetext{
${ }^{2}$ Unless otherwise noted, we are using the term SciCommers to refer to SciComm professionals collectively, including trainers, practitioners, researchers and evaluators. Within this perspective, we also identify specific action items for SciComm trainers.
} 
TABLE 1 | List of White Supremacy Culture characteristics identified by Jones and Okun (2001) and examples of how these show up in STEM fields.

\begin{tabular}{|c|c|c|}
\hline $\begin{array}{l}\text { Characteristics of White } \\
\text { Supremacy Culture } \\
\text { (adapted from Jones and } \\
\text { Okun, 2001) }\end{array}$ & Descriptions of the characteristic & $\begin{array}{l}\text { Consequences of the characteristic for scientists, the } \\
\text { scientific enterprise, and/or SciComm }\end{array}$ \\
\hline
\end{tabular}

Defensiveness

Either/or thinking

Fear of open conflict

Individualism/l'm the only one

Objectivity

Only one right way

Paternalism

Perfectionism

Power hoarding

Quantity over quality/progress is bigger, more

Right to comfort

Sense of urgency

Worship of the written word
White people spend energy defending against charges of racism instead of examining how racism is actually happening.

Energy in the organization is spent ensuring that feelings are not hurt, or working around defensive people.

Results in trying to simplify complex things.

Emphasis on false politeness, oblivious to offense; insisting on politeness as terms for conversation or negotiation.

The belief that if something is going to get done right, "I" am the one to do it; a belief that if the outcome is celebrated, I should be the one to take credit (even if others were involved).

Desire for individual recognition and credit.

Impatience with any thinking that does not appear "logical." The belief that emotions are inherently destructive, irrational, and should not play a role in decision-making or group process.

The belief there is one right way to do things and once people are introduced to the right way, they will see the light and adopt it.

Those with power often don't think it is important or necessary to understand the viewpoint or experience of those for whom they are making decisions.

Making a mistake is confused with being a mistake, doing wrong with being wrong.

Little appreciation expressed among people for the work that others are doing. Appreciation that is expressed usually directed to those who get most of the credit anyway.

Power is viewed as a zero-sum game; only few people can have it, it cannot be shared. Those with power assume they have the best interests of the organization at heart and discount other viewpoints.

Downplays the monetary and non-monetary costs of bigger/more. Ignores ways in which people may be exploited, excluded, or underserved.

Values product over process, productivity over engagement.

Discomfort with emotion and feelings.

The belief that those with power have a right to emotional and psychological comfort.

Pressure to quickly produce highly visible results.

The organization only values highly cited publications, and does not value other ways in which information gets shared.
Results in leaders of STEM institutions focusing their attention on addressing individual or small-scale instances of racism, while ignoring or reinforcing systemic biases in the institutions and practices of science.

Creates reluctance to work with students or colleagues if they question WSC in science.

Encourages single-factor explanations, ignoring complexities of systems/processes and leading to oversimplified science.

Leads to insincerity in interactions; mistrust among scientists and between scientists and public audiences.

Reduces collaboration, increases competition, and cultivates the belief that science and science communication is done by "superstars" acting alone.

Reinforced by institutional rewards for being a single author or senior author. Leads to a small number of people getting most of the credit, forgetting that science is built upon the work of others; also associated with overestimating one's own scientific knowledge or competence.

Ignores human propensity for System 1 thinking.

Makes science inaccessible; Ignores the science indicating that emotions are inherent and necessary in human decision-making.

Generates deficit model communication and a tendency to blame audiences for failure to understand.

Leads to science communication that is perceived as tone-deaf, insensitive, or irrelevant by audiences with significantly different experiences from the leadership. Leads to alienating scientists, science communicators, and audiences whose experiences differ from the dominant narrative. Loss of creativity and talent from science and science communication.

Leads to reluctance to engage in SciComm if scientists are concerned that their research may not meet high standards or if they are concerned that they will make mistakes in their SciComm. Selectively encourages those who have received extensive validation from the scientific enterprise to seek out SciComm training because they are less likely to feel that their mistakes will be seen as shortcomings, while discouraging others.

Introduces secondary agendas to maintain the status-quo. Reinforces the myth of meritocracy. Gatekeepers play an outsized role in determining what ideas are elevated.

Causes scientists to focus on their own agendas and needs rather than the audience's issues and needs.

Prioritizes of research and publications; devaluing of public outreach or community-based projects.

Feeds the stereotype that scientists are cold, impersonal, and distant.

Makes a person the problem, causing scapegoating and gaslighting. Denies experiences and emotions of scientists and science communicators.

Sacrifices relationship-building in favor of action, including relationships between researchers and diverse communities or stakeholders.

Reinforces the publish or perish mentality. Networks, collaborations, activities, and outputs are only valued if they are connected to established practices or traditional formats. 


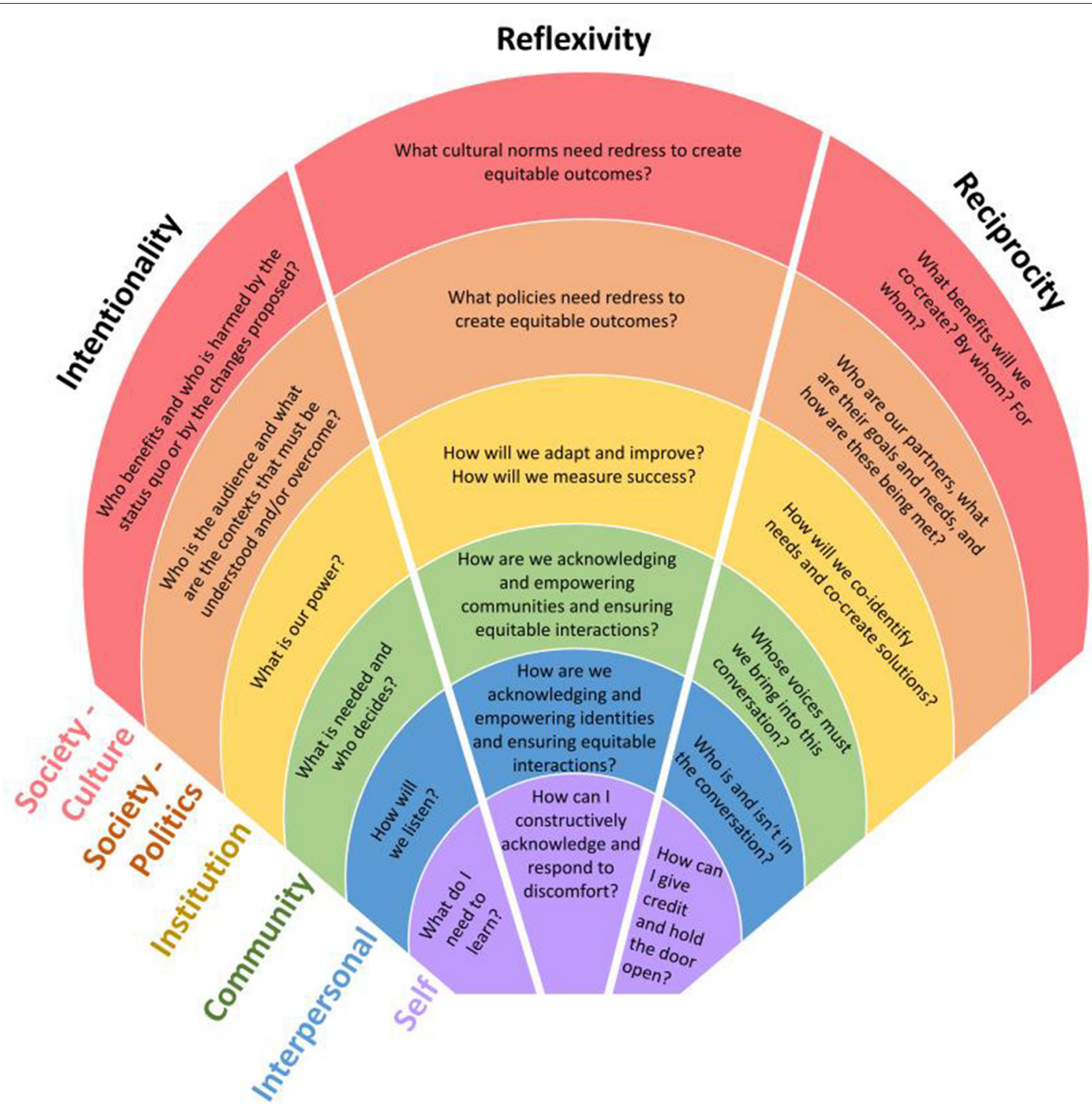

FIGURE 1 | Concept for co-creating a framework to guide authentic, culturally competent, and inclusive SciComm. In this figure, spheres of influence are represented as arcs of color, from self at center, to society-culture at the outer ring. The arcs are divided into three sections, each representing one of three traits of inclusive science communication (intentionality, reflexivity, and reciprocity) as marked at the top of each section. Each intersection of a sphere of influence and trait of Inclusive SciComm contains a question. Each question is a prompt to consider, for developing inclusive science communication trainings, workshops, and interactions. The draft prompts here are still in development and are intended as representative examples.

\section{How Does WSC Persist in STEM?}

Some argue that science is neutral, objective, and even "colorblind." These suggestions fail to explain persistent disparities in STEM (Table 2). Biases are frequently invisible to dominant groups who do not experience them personally (Henry, 2010). Dominant groups hold most leadership roles in STEM; accordingly, the biases in STEM are frequently invisible to those in power, leadership, and decision-making roles.

Racial disparities in STEM are the most visible evidence and most urgent reminder of racism and WSC in STEM Institutions. Cultural norms, values, beliefs, and standards give institutional power to White scientists, and enable them to maintain power and advantages over minitorized groups.

Biased standards of practice in STEM are inherited, not affirmatively chosen, co-produced, or inclusively designed. They persist when cultural dynamics designed to center a White norm (Lee, 2020; McGee, 2020) interact with cognitive biases in hiring and advancement (Linos and Reinhard, 2015); they create a sleight of hand that the dominant culture has branded "merit" (Markovits, 2019). WSC invisibly ensures White majority scientists who protect the status quo continue to hold most decision-making and power-holding roles in STEM (Johnson and Howsam, 2020; McGee, 2020; Gee and Hicken, 2021). Such 
practices permeate institutional design; they benefit few and harm many. Although these norms harm people regardless of identity, people who are Black, Indigenous, Latinx, and other minoritized identities are harmed most.

STEM institutions persistently fail to account for the influences of WSC on STEM research and institutional culture. This error is caused by a disproportionate focus on intentional acts of racism [i.e., Explicitly holding Black, Indigenous, Latinx, and minoritized researchers and scholars to a different stsandard from White academics for hiring and funding decisions (e.g., Lewis, 2020; Rucks-Ahidiana, 2021)]; unintentional acts of racism [hiring choices based on subjective categories like "fit" (e.g., Milkman et al., 2015)]; and other biases perpetuated by individuals within organizations. By unquestioningly accepting institutional standards of practice, we uphold structures that are intended to be neutral but unintentionally perpetuate and accentuate bias (e.g., Hoppe et al., 2019; Stevens et al., 2021; Taffe and Gilpin, 2021) ${ }^{3}$.

When considering institutions, we focus on intent (such as scientific rigor or objectivity) and ignore the evidence that systems designed by White scientists favor White scientists. For example, per Hoppe et al. (2019), majority White review panels direct funding to topics disproportionately preferred by White applicants. Accordingly, NIH grant applications with White PIs are 1.7 times more likely to be funded than applications with Black PIs, and this gap has persisted unchanged for nearly a decade (Hoppe et al., 2019; Taffe and Gilpin, 2021). We amplify this bias by using grants and manuscripts as criteria for hiring and promotion (Stevens et al., 2021; Taffe and Gilpin, 2021) and as a basis for merit pay bonuses (Harvard University, 2021).

\section{What Is the Role of Scicomm?}

Patterns and practices of SciComm have set the stage for a series of myths about science and scientists that perpetuate WSC. The cultural ideology of science as unbiased truth generates the notion of what author Chimamanda Ngozi Adichie refers to as a "single story" (Adichie, 2009). SciComm around that "single story" typically represents a White-centered narrative of science as objective truth and a benevolent force. SciComm can also amplify the myths of meritocracy and solitary genius, by telling stories focused on innovative protagonists who singlehandedly make novel discoveries and earn esteem within the academy. This ignores the realities that advancement results from a mix of effort, abilities, and social factors (McNamee, 2014), and science is a team effort (Wuchty et al., 2007); most research is achieved via contributions from students, staff, and collaborators, whose efforts often accrue to a single senior scientist (Clark, 2017). SciCommers also disproportionately amplify science by White researchers (Dawson, 2018), which unintentionally reinforces the power of normal (Fuentes, 2014) enjoyed by White scientists, and creates associations between whiteness and authority, accomplishment, and skill (Dutt, 2018). These false ideas tilt science toward the WSC characteristics of

\footnotetext{
${ }^{3} \mathrm{We}$ also acknowledge that these issues intersect with and can be amplified by perspective, positionality, and cognitive biases; however, here in this manuscript we are focusing specifically on the role of WSC.
}

perfectionism, individualism, defensiveness, and the idea that there is only one right way, prioritizing a focus on "inadequacies" while giving credit to those who are already centered.

\section{DISCUSSION}

\section{How We Create Change}

We call upon SciComm trainers to be models for mitigating WSC in SciComm, STEM, and society, starting with four core themes for action: (1) Authentic Interrogation, Acknowledgment, and Accountability; (2) Representation; (3) Culturally Responsive Practice; and (4) Inclusion. In considering these themes, we must also consider how we match actions within each of our spheres of influence, from self, to interpersonal, to community, to institution, to society: politics and culture.

This work must start with awareness; opening our eyes to the issues and acknowledging the ways we collectively contribute to and perpetuate them. Authentic Interrogation, Acknowledgment, and Accountability requires SciCommers to explicitly articulate the ways in which STEM and SciComm have been used as systems of oppression, upholding WSC. Beyond confronting the ways in which the scientific enterprise and field of SciComm have maintained WSC, SciCommers can reflexively examine their own work to identify ways in which their organizations and practices in particular have been complicit in perpetuating it. This includes acknowledging both current and past harms before attempting to move forward. In addition to interrogating and acknowledging WSC traits and myths when they are visible in our work, we can begin to create systems of accountability, which should be formalized over time as we become more adept at recognizing the problems.

Prioritizing Representation provides another avenue for dismantling WSC in STEM and SciComm. Scientists of color continue to be underrepresented. Similarly, SciComm content commonly focuses on issues not of concern to marginalized communities (Dawson, 2018). Communicators must proactively showcase work done by scientists of color. Not only is it crucial to convey (in all forms of media) the diversity of scientists, it is also important to examine the narratives or myths that are being conveyed in the process. Additionally, we need to showcase topics and issues in science that will benefit and advance knowledge in diverse communities. SciComm trainers, specifically, can call out the importance of diverse representation in their trainings, and they can also model it by ensuring that all examples and exercises they include in their curricula represent scientists with a wide range of identities and backgrounds.

Representation also includes thinking about who is visible. Scientists who communicate regularly or whose work is featured more with public audiences tend to be more visible within and beyond the scientific enterprise. This visibility can bring a number of additional benefits, including more citations and greater likelihood of earning awards and recognition, which validate their efforts, and ultimately increase their funding opportunities. These types of recognitions perpetuate the cycle of people with more privilege having greater access to the opportunities, resources, and platforms to do more SciComm. 
TABLE 2 | Common perceptions about inequality in STEM institutions (a) can be evaluated via associated expectations (b). However, persistent disparities in STEM (c) suggesting that STEM institutions are not "colorblind," and that racism in STEM is a systemic cultural problem.

\begin{tabular}{ll}
\hline (a) If this is true & (b) Then we expect \\
\hline STEM Institutions are "colorblind." & $\begin{array}{l}\text { Demographics of STEM institutions would reflect the } \\
\text { demographics of the general population. } \\
\text { Funding and pay would not correlate with race. }\end{array}$
\end{tabular}

Racism in STEM primarily occurs via discrete, isolated instances of discriminatory behaviors. In other words, racism is perpetuated by a few "bad apples."
Taking action to resolve isolated incidents of racism would result in diverse, equitable STEM institutions.

\section{(c) But the reality is}

Black scientists are underrepresented in STEM careers, as are Latinx and Indigenous scientists (Fry et al., 2021). White scientists benefit from a funding advantage (Hoppe et al., 2019; Stevens et al., 2021; Taffe and Gilpin, 2021) and a pay advantage (Li and Koedel, 2017; Fry et al., 2021).

Persistent racial disparities have not changed much over time (Taffe and Gilpin, 2021).
Lastly, representation applies not only to whose work is being communicated about, but also to communicators themselves. SciComm trainers have a role to play in diversifying the pool of science communicators. Trainers can do this by prioritizing trainings for Black, Indigenous, and Latinx researchers and reducing barriers to participation, for example by finding ways to reduce or eliminate costs and scheduling trainings at times and places that are convenient to scientists of color. In addition to reducing logistical barriers to participation, trainers can break down psychological barriers by ensuring that the training is as inclusive as possible. The 500 Women Scientists Guide to Inclusive Science Meetings (Pendergrass et al., 2019) is a good starting place, and the Inclusive SciComm community has assembled additional resources on this topic (see "Conference and Meeting Planning") (Inclusive SciComm, 2020). Furthermore, trainers must demand that the field of SciComm training itself become more diverse, which will facilitate broader representation in trainees and in the scientists whose stories are told. Again, this can be done by intentionally reducing barriers to entry into the field.

The next strategy includes shifting to a more Culturally Responsive SciComm Practice. Culture is how we make sense of the world and greatly influences how we see it, how we try to understand it, and how we communicate with each other. Cultural responsiveness involves considering how to incorporate the many aspects that an audience brings with them to a learning experience and further demonstrating how diversity is valued. This includes placing value on cultural competency, the ability to understand, honor, appreciate, and respect the values, beliefs, attitudes, and behaviors of those from cultures different from our own (Roberts, 1990; DeAngelis, 2015). Further, the cultural contexts in which someone learns affects how they interpret the content shared with them (Guild, 1994; Futterman, 2015; Lynch, 2016; Pusey, 2018). As such, SciComm experiences should prioritize diverse representation (as mentioned above), and also different ways of knowing, experiences, and understanding that will allow audiences to find and value their own voices, histories, and cultures. In order to do this, SciCommers must know their audiences - this is necessary scaffolding for effective communication with any group. Knowing your audience also involves understanding where their interests lie and what matters most to them, by asking. Though the deficit model still persists in many science communication spheres, it is now time for us to transition toward something that is more engaging: two-way communication, a dialog where SciCommers and audiences can both be heard (Trench, 2008; Dudo et al., 2021). To be successful at cultural responsiveness, SciCommers need to evaluate the cultural contexts through which we present our content, and incorporate methods of engagement that can accommodate various belief systems and cultural perspectives.

The prior themes feed into the final one of Inclusivity, which can be achieved by creating a climate for diversity. We need to work collectively to improve the current climate by reducing attitudes of hostility and competition that are pervasive among STEM fields, including SciComm. We must also decrease the sense of exclusion that is felt by marginalized communities. Creating authentic inclusion will lead to a more positive climate and contribute to increased sense of belonging and visibility. As Verna Meyers said, "Diversity is being invited to the party; inclusion is being asked to dance," (per Cho, 2016). This will also include actions such as (but not limited to) authentic collaboration and co-creation with marginalized communities that includes a seat at the table with equal weight as other members; actively challenging and dismantling the oppressive systems in place, particularly when you can speak from a position of power, privilege, or status; and always holding ourselves and others accountable for actively and continually progressing in this work. As articulated by Canfield and Menezes (2020), inclusive SciComm is characterized by three Key Traits. The first is intentionality, the intentional consideration of our audiences, how "science" is defined, and how marginalized identities are, and have been, represented and supported. Second is reciprocity, interactions between science communicators and audiences that address past and present inequities through equal partnerships marked by co-creation and recognition of the assets and varied forms of expertise communities bring with them. Reflexivity is the third key trait and describes the continuous, critical, and systematic reflection on the communicators' and audiences' personal identities, practices, and outcomes, coupled with adaptation as needed to redress inequitable interactions. We will further explore how these Key Traits can be incorporated in this work below. 


\section{Next Steps}

Incorporating authentic interrogation, acknowledgment, and accountability, increasing representation, creating a culturally responsive practice, and furthering inclusion will require creating, testing, and applying new approaches and new frameworks in SciComm. Transcending WSC will also require making changes across levels of societal influence, ranging from individual, at the most proximal, to societal-cultural, at the broadest. Our team has begun building a framework based on applying the Key Traits of Inclusive SciComm (Canfield and Menezes, 2020) across levels of societal influence, that is intended to guide authentic, culturally competent, and inclusive SciComm. The goal is to use SciComm to supplant WSC in science and society with new co-created norms centering minoritized scholars, SciCommers, and audiences in STEM.

The framework crosses the three Key Traits (intentionality, reciprocity, and reflexivity) with six levels of influence (individual, interpersonal, community, organizational or institutional, societal-policy, and societal-cultural). At each intersection of a Key Trait and level of influence, we articulate questions that SciCommers can ask themselves and considerations to be aware of to help them assess the extent to which their practice aligns with the themes for actions (Figure 1). Creating the framework is an iterative process. In October of 2021, our team led a brainstorming and collaboration session with participants at the Inclusive SciComm symposium to study the problem of WSC in SciComm and STEM, consider the value of the framework as a possible solution, and iterate on how to improve it (Callwood et al., 2022). We anticipate continued co-creation with SciCommers in the future, to ensure that the framework is as useful as possible to those who aim to dismantle WSC through SciComm and SciComm training.

We welcome collaboration and feedback on this work in progress: we see this work as ongoing, iterative, interactive, and open-source. We also hope other collaborations are exploring avenues for mitigating WSC in SciComm. Just as

\section{REFERENCES}

\#BlackInSciComm (2020). Black in Science Communication. Available online at: https://www.blackinscicomm.com/ (accessed September 30, 2021).

500 Women Scientists (2016). Available online at: https://500womenscientists.org/ (accessed September 29, 2021).

Academics for Black Survival and Wellness (2020). Available online at: https:// www.academics4blacklives.com/ (accessed September 29, 2021).

Adichie, C. N. (2009). The Danger of a Single Story [Conference presentation] TEDGlobal 2009. Oxford. Available online at: https://www.ted.com/talks/ chimamanda_ngozi_adichie_the_danger_of_a_single_story (accessed September 29, 2021).

Baxter, R. (2021). Culturally responsive science communication: the messengers, messages, and voices in communicating science through hip-hop (dissertation defense seminar), University at Buffalo Graduate School of Education, Buffalo, NY.

Bryant, J., Cohen-Stratyner, B., Mann, S., and Williams, L. (2021). The White Supremacy Elephant in the Room. American Alliance of Museum. Available online at: https://www.aam-us.org/2021/01/01/the-white-supremacyelephant-in-the-room/ (accessed September 29, 2021).
SciCommers have shifted the culture of STEM already, we know SciComm can continue to lead on dismantling WSC in STEM.

We are grateful to all of our teachers from whom we are continuing to learn, and who inspire us in this ongoing work. We are particularly inspired by and learning from new resources and perspectives on inequality in STEM and what we can do about it (\#BlackInSciComm, 2020; Canfield et al., 2020; Lee, 2020; McGee, 2020; Baxter, 2021; Easley, 2021). We hope that SciCommers will join us to work on the framework we are developing, and/or to develop additional liberating strategies that work to dismantle WSC in science and in society, while creating and maintaining a climate for diversity.

\section{DATA AVAILABILITY STATEMENT}

The original contributions presented in the study are included in the article/supplementary material, further inquiries can be directed to the corresponding author.

\section{AUTHOR CONTRIBUTIONS}

$\mathrm{KC}$ and MW conceived the original concept for and wrote the original draft of this manuscript. KC, MW, TT, and RH wrote, reviewed, and edited the manuscript. All authors contributed to the article and approved the submitted version.

\section{ACKNOWLEDGMENTS}

The authors wish to thank the Science Communication Trainers Network for creating the space and opportunity for convening our team, as well as the Inclusive SciComm community for foundational work in making science communication and STEM more inclusive. The authors also thank two reviewers for comments that helped strengthen the manuscript.

Callwood, K., Weiss, M., Hendricks, R., Taylor, T., and Co-creating a Framework Workshop (2022). Co-creating a Framework to Embed the Key Traits of Inclusive SciComm in Science Communication Training, Practice, and Evaluation, Workshop Report. Available online at: https://bit.ly/WorkshopReport (accessed January 18, 2022).

Canfield, K., and Menezes, S. (2020). The State of Inclusive Science Communication: A Landscape Study. Kingston, RI: Metcalf Institute, University of Rhode Island. Available online at: https://digitalcommons.uri.edu/nrs_facpubs/184 (accessed September 29, 2021).

Canfield, K. N., Menezes, S., Matsuda, S. B., Moore, A., Mosley Austin, A. N., Dewsbury, B. M., et al. (2020). Science communication demands a critical approach that centers inclusion, equity, and intersectionality. Front. Commun. 5, 2. doi: $10.3389 /$ fcomm.2020.00002

Cheney, I., and Shattuck, S. (Directors). (2020). Picture a Scientist [Film]. Uprising, LLC.

Cho, J. H. (2016). Diversity Is Being Invited to the Party and Asked to Dance. Available online at: https://www.cleveland.com/business/2016/05/diversity_is_ being_invited_to.html (accessed September 30, 2021).

Christopherson, E. G., Scheufele, D. A., and Smith, B. (2018). The civic science imperative. Stanf. Soc. Innov. Rev. 16, 46-52. doi: 10.48558/6K46-1C68 
Clark, K. (2017). Myth of the genius solitary scientist is dangerous. The Conversation. Available online at: http://theconversation.com/myth-of-thegenius-solitary-scientist-is-dangerous- 87835 (accessed September 30, 2021).

Dawson, E. (2018). Reimagining publics and (non) participation: Exploring exclusion from science communication through the experiences of low-income, minority ethnic groups. Public Underst. Sci. 27, 772-786. doi: $10.1177 / 0963662517750072$

DeAngelis, T. (2015). In search of cultural competence. Monit. Psychol. 46:22. doi: 10.1037/e520422015-022

Dudo, A., Besley, J. C., and Yuan, S. (2021). Science communication training in North America: preparing whom to do what with what effect? Sci. Commun. 43, 33-63. doi: 10.1177/1075547020960138

Dutt, K. (2018). How implicit bias and lack of diversity undermine science. Scientific American. Available online at: https://blogs.scientificamerican. com/voices/how-implicit-bias-and-lack-of-diversity-undermine-science/ (accessed September 29, 2021).

Easley, T. R. (2021). Mind/Heart for Diversity. New York, NY: DIO Press, Inc.

Fry, R., Kennedy, B., and Funk, C. (2021). STEM Jobs See Uneven Progress in Increasing Gender, Racial and Ethnic Diversity. Washington, DC: Pew Research Center.

Fuentes, A. (2014). Why normal is a myth. Psychology Today. Available online at: https://www.psychologytoday.com/us/blog/busting-myths-about-humannature/201403/why-normal-is-myth (accessed September 29, 2021).

Futterman, L. (2015). Beyond the classroom: The impact of culture on the classroom. Miami Herald. Available online at: https://www.miamiherald.com/ news/local/community/miami-dade/community-voices/article36727782.html (accessed September 29, 2021).

Gee, G. C., and Hicken, M. T. (2021). Structural racism: The rules and relations of inequity. Ethn. Dis. 31, 8. doi: 10.18865/ed.31.S1.293

Guild, P. (1994). The culture/learning style connection. Educ. Leadersh. 51, 16-21.

Handley, I. M., Brown, E. R., Moss-Racusin, C. A., and Smith, J. L. (2015). Quality of evidence revealing subtle gender biases in science is in the eye of the beholder. Proc. Natl. Acad. Sci. U.S.A. 112, 13201-13206. doi: 10.1073 /pnas. 1510649112

Harvard University (2021). Faculty Academic Salary Incentive Program (FASIP) for Sponsored Awards. Available online at: https://research.fas.harvard.edu/files/ research/files/fasip_policy_revised_april_2021.pdf?m=1619109145 (accessed September 30, 2021).

Henry, P. J. (2010). "Institutional bias," in The SAGE Handbook of Prejudice, Stereotyping and Discrimination, eds J. F. Dovidio, M. Hewstone, P. Glick, and V. M. Esses (London: SAGE Publications Ltd.), 426-440. doi: 10.4135/9781446200919.n26

Hoppe, T. A., Litovitz, A., Willis, K. A., Meseroll, R. A., Perkins, M. J., Hutchins, B. I., et al. (2019). Topic choice contributes to the lower rate of NIH awards to African-American/Black scientists. Sci. Adv. 5, eaaw7238. doi: $10.1126 /$ sciadv.aaw7238

Inclusive SciComm (2020). Inclusive SciComm Resources. Available online at: https://docs.google.com/document/d/ 1g7uXZzsC1QBCZWz4cRsERyzf6CrLKVXyLM_MTquxK4A/edit (accessed September 30, 2021).

Johnson, G. F., and Howsam, R. (2020). Whiteness, power and the politics of demographics in the governance of the Canadian academy. Can. J. Polit. Sci. 53, 676-694. doi: 10.1017/S0008423920000207

Jones, K., and Okun, T. (2001). White Supremacy Culture. Available online at: https://www.whitesupremacyculture.info/uploads/4/3/5/7/43579015/okun_-_ white_sup_culture_2020.pdf (accessed September 29. 2021).

Lee, D. N. (2020). Diversity and inclusion activisms in animal behaviour and the ABS: A historical view from the U.S.A. Anim. Behav. 164, 273-280. doi: $10.1016 /$ j.anbehav.2020.03.019

Lewis, N. A. (2020). What I've learned about being a Black scientist. Science. Available online at: https://www.science.org/content/article/what-ive-learnedabout-being-black-scientist (accessed September 30, 2021).

Li, D., and Koedel, C. (2017). Representation and salary gaps by raceethnicity and gender at selective public universities. Educ. Res. 46, 343-354. doi: 10.3102/0013189X17726535
Linos, E., and Reinhard, J. (2015). A Head for Hiring: Behavioural Science of Recruitment and Selection. London: Chartered Institute of Personnel and Development (CIPD).

Lynch, M. (2016). Examining the impact of culture on academic performance. The Edvocate. Available online at: https://www.theedadvocate.org/examining-theimpact-of-culture-on-academic-performance/ (accessed September 29, 2021).

Markovits, D. (2019). The Meritocracy Trap: How America's Foundational Myth Feeds Inequality, Dismantles the Middle Class, and Devours the Elite. New York, NY: Penguin Press.

McGee, E. O. (2020). Black, Brown, Bruised: How Racialized STEM Education Stifles Innovation. Cambridge, MA: Harvard Education Press.

McNamee, S. (2014). The meritocracy myth revisited. Sociat. Today 12. Available online at: http://www.ncsociology.org/sociationtoday/v122/merit.html

Milkman, K. L., Akinola, M., and Chugh, D. (2015). What happens before? A field experiment exploring how pay and representation differentially shape bias on the pathway into organizations. J. Appl. Psychol. 100, 1678-1712. doi: 10.1037/apl0000022

Ortega, R. P. (2021). Black scientists gather to form communities and boost diversity in science. Nat. Med. 27, 756-758. doi: 10.1038/s41591-02101315-8

Pendergrass, A., Zelikova, J., Arnott, J., Bain, H., Barnes, R., Baron, J., et al. (2019). Inclusive Scientific Meetings: Where to Start. Boulder, CO: 500 Women Scientists.

Pusey, S. (2018). How does culture impact our ability to learn? ESchool News. Available online at: https://www.eschoolnews.com/2018/04/17/cultureimpact-ability-learn/ (accessed September 29, 2021).

Roberts, R. N. (1990). Developing Culturally Competent Programs for Families of Children With Special Needs. Washington, DC: Georgetown University Child Development Center.

Rucks-Ahidiana, Z. (2021). The Systemic Scarcity of Tenured Black Women. High. Ed. Available online at: https://www.insidehighered.com/advice/2021/ 07/16/black-women-face-many-obstacles-their-efforts-win-tenure-opinion (accessed September 30, 2021).

Stevens, K. R., Masters, K. S., Imoukhuede, P. I., Haynes, K. A., Setton, L. A., Cosgriff-Hernandez, E., et al. (2021). Fund Black scientists. Cell 184, 561-565. doi: 10.1016/j.cell.2021.01.011

Taffe, M. A., and Gilpin, N. W. (2021). Racial inequity in grant funding from the US National Institutes of Health. eLife 10, e65697. doi: 10.7554/eLife.65697

Trench, B. (2008). Towards an analytical framework of science communication models, in Communicating Science in Social Contexts, eds. D. Cheng, M. Claessens, T. Gascoigne, J. Metcalfe, B. Schiele, and S. Shi (Dordrecht: Springer Netherlands), 119-135.

Wuchty, S., Jones, B. F., and Uzzi, B. (2007). The increasing dominance of teams in production of knowledge. Science 316, 1036-1039. doi: $10.1126 /$ science. 1136099

Conflict of Interest: All authors declare this article was written in the absence of any commercial or financial relationships that could be construed as a conflict of interest.

Publisher's Note: All claims expressed in this article are solely those of the authors and do not necessarily represent those of their affiliated organizations, or those of the publisher, the editors and the reviewers. Any product that may be evaluated in this article, or claim that may be made by its manufacturer, is not guaranteed or endorsed by the publisher.

Copyright (c) 2022 Callwood, Weiss, Hendricks and Taylor. This is an open-access article distributed under the terms of the Creative Commons Attribution License (CC BY). The use, distribution or reproduction in other forums is permitted, provided the original author(s) and the copyright owner(s) are credited and that the original publication in this journal is cited, in accordance with accepted academic practice. No use, distribution or reproduction is permitted which does not comply with these terms. 